FERRAZ, RM; RAGASSI, CF; HEINRICH, AG; LIMA, MF; PEIXOTO, JR; REIFSCHNEIDER, FJB. 2016. Caracterização morfoagronômica preliminar de acessos de pimentas cumari. Horticultura Brasileira 34: 498-506. DOI - http://dx.doi.org/10.1590/S0102-053620160408

\title{
Caracterização morfoagronômica preliminar de acessos de pimentas cumari
}

\author{
Rodrigo M Ferraz'; Carlos F Ragassi²; Ana G Heinrich ${ }^{1}$; Mirtes F Lima² ${ }^{2}$ José R Peixoto후 Francisco JB \\ Reifschneider ${ }^{2}$ \\ ${ }^{1}$ Universidade de Brasília (UnB), Brasília-DF, Brasil; ferraz.rodrigo.89@gmail.com; aninha_glaucia@hotmail.com; peixoto@unb.br; \\ ${ }^{2}$ Embrapa Hortaliças, Brasília-DF, Brasil; carlos.ragassi@embrapa.br; mirtes.lima@embrapa.br; francisco.reifschneider@embrapa.br
}

\section{RESUMO}

A pimenta cumari, Capsicum baccatum var. praetermissum e C. baccatum var. baccatum, é uma espécie semidomesticada, endêmica das regiões Sudeste e Centro-Oeste do país. Apesar da sua importância econômica, principalmente para a agricultura familiar, e da sua ampla variabilidade, ainda não existe uma cultivar dessa espécie disponível no mercado brasileiro. Este trabalho teve como objetivo avaliar acessos de pimenta cumari do Banco de Germoplasma de Capsicum da Embrapa Hortaliças com base em características morfoagronômicas e identificar acessos promissores que possam dar origem a um programa de melhoramento genético. Verificou-se a existência de grande variabilidade entre os acessos analisados, tendo sido encontradas diferenças para a maioria das variáveis. O material mais precoce, $\mathrm{CNPH} 4065$, floresceu aos 81 dias após a semeadura e o mais tardio, CNPH 2957, aos 126 dias. O número de flores por axila variou de 1 a 3 . Já em relação à pilosidade, a quantidade de plantas muito pilosas foi de 6,25\%; pilosidade moderada $6,25 \%$; pouca pilosidade $12,50 \%$ e sem pilosidade $75,00 \%$. A estimativa da produtividade variou de 8 a 340 gramas por planta e a incidência de viroses indicou o PepYMV como o mais frequente, tendo sido encontrado em 33\% das plantas analisadas. Os acessos CNPH 4065, CNPH 3824, CNPH 3993, CNPH 2964 e CNPH 2948 foram considerados promissores para o uso em programa de melhoramento.

Palavras-chave: Capsicum baccatum, precocidade, variabilidade.

\begin{abstract}
Preliminary morpho-agronomic characterization of cumari hot peppers

The cumari hot pepper, Capsicum baccatum var. praetermissum and $C$. baccatum var. baccatum, is a semi-domesticated species, endemic to the Southeast and Midwest regions of Brazil. Despite its economic importance, especially for small farmers in family agriculture systems, no cumari cultivars are available in the Brazilian market. This research aimed to evaluate 16 cumari accessions of the Capsicum Germplasm Bank of Embrapa Vegetables based on morpho-agronomic features, and identify promising accessions for further breeding programs. Genetic variability was found among accessions and differences were observed for the majority of the characteristics. The earliest genotype, CNPH 4065, set flowers 81 days after sowing and the latest, CNPH 2957, at 126 days. The number of flowers per axil ranged from 1 to 3 . Pubescence, a relevant plant characteristic associated to insect resistance was found as follows: highly pubescent plants $6.25 \%$; moderately pubescent $6.25 \%$; almost glabrous $12.50 \%$; and glabrous $75.00 \%$. Yield was estimated in between 8 grams/plant and 340 grams/plant. PepYMV $33 \%$ of the total number of plants) was the most prevalent virus infecting cumari hot peppers in the field. Five accessions (CNPH 4065; CNPH 3824; CNPH 3993; CNPH 2964; CNPH 2948) were considered as promising to be used in cumari breeding programs.
\end{abstract}

Keywords: Capsicum baccatum, earliness, variability.

(Recebido para publicação em 5 de junho de 2015; aceito em 2 de abril de 2016) (Received on June 5, 2015; accepted on April 2, 2016)

\begin{abstract}
$\mathrm{A}^{\mathrm{s}}$ s pimentas do gênero Capsicum possuem grande destaque na economia mundial e têm despertado interesse do mercado em consequência da rica diversidade de tipos, sabores, cores e aromas (DeWitt \& Bosland, 2009). O vasto aproveitamento comercial das pimentas Capsicum engloba a comercialização de frutos in natura ou processados na forma de molhos, conservas, geleias e pápricas, assim como também, a venda de plantas ornamentais e o emprego na fabricação de
\end{abstract}

medicamentos e cosméticos. No Brasil, o mercado de produtos derivados de espécies do gênero Capsicum representa fatia importante do agronegócio de hortaliças. Apesar das dificuldades em se estimar com exatidão os dados de produção dos diferentes tipos de pimentas, principalmente pelo fato do mercado ser segmentado com variados usos e formas de consumo, para o ano de 2010 , a produção mundial de pimenta foi de, aproximadamente, 30,6 milhões de toneladas colhidas em 3,8 milhões de hectares (FAO, 2012).

Este gênero apresenta grande diversidade genética e possui mais de 30 espécies identificadas. Entretanto, apenas as espécies Capsicum annuum, C. baccatum, $C$. frutescens, $C$. chinense e $C$. pubescens são consideradas domesticadas (DeWitt \& Bosland, 2009). A classificação dessas espécies dentro do gênero foi feita, principalmente, com base em características morfológicas das flores e dos frutos e também no nível de domesticação da espécie, ou 
seja, no grau de dependência da planta ao homem (Carvalho et al., 2003).

No Brasil, a pimenta cumari, Capsicum baccatum var. praetermissum e C. baccatum var. baccatum, tem sido objeto de interesse crescente por parte dos produtores, que vislumbram na sua produção alto retorno financeiro, obtido principalmente por meio da venda de pimentas em conservas. Entretanto, a cadeia produtiva da pimenta cumari ainda é carente de informações que orientem a obtenção de produção padronizada, estável e de qualidade. Em campo, é possível verificar que entre os principais desafios enfrentados pelos produtores destacam-se desuniformidade das plantas e dos frutos; tempo requerido para germinação das sementes; falta de cultivares registradas; deiscência dos frutos quando maduros; ataque dos frutos por pássaros e incidência de viroses (Ribeiro et al., 2008).

Trabalhos de caracterização morfológica e agronômica dos genótipos disponíveis em bancos de germoplasma, tais como o presente estudo, visam dar suporte ao desenvolvimento de programas de melhoramento genético e, dessa forma, contribuir para a solução dos desafios da cultura. O Banco de Germoplasma da Embrapa Hortaliças, iniciado há mais de 30 anos, atualmente é o maior do gênero Capsicum no país e possui acessos com significativa representatividade da biodiversidade das variedades botânicas de cumari. Possui, aproximadamente, 4.200 materiais, entre cultivares de polinização aberta, híbridos, populações de materiais cultivados, linhagens e materiais silvestres, representados, principalmente, pelas espécies Capsicum annuum, C. baccatum, C. chinense e $C$. frutescens, oriundos das diversas regiões brasileiras, assim como também de outros países. A coleção é utilizada, principalmente, em programas de melhoramento genético, dando suporte ao desenvolvimento de novas cultivares para atender às demandas do mercado.

O presente estudo teve como objetivo caracterizar morfologicamente e agronomicamente acessos de pimenta cumari do Banco de Germoplasma de Capsicum da Embrapa Hortaliças, visando identificar materiais com ca- racterísticas superiores, com os quais seria possível iniciar um programa de melhoramento genético da cultura.

\section{MATERIAL E MÉTODOS}

Acessos - Foram avaliados 16 acessos (Tabela 1) de pimenta cumari pertencentes ao Banco de Germoplasma de Pimentas da Embrapa Hortaliças, divididos em dois grupos: Grupo I= Capsicum baccatum var. praetermissum; Grupo $\mathrm{II}=$ C. baccatum var. baccatum, sendo seis acessos do Grupo I e oito acessos do Grupo II. Dois acessos, CNPH 4382 e CNPH 4065, ainda não classificados em nível de variedade botânica dentro da espécie, completaram o conjunto de 16 acessos. Estes materiais abrigam considerável parte da biodiversidade da espécie no país, considerando a abrangência geográfica, pois foram coletados em quatro diferentes estados, entre os quais, Minas Gerais, com o maior número de representantes (nove acessos provenientes de seis municípios distintos).

Experimento em campo - O ensaio foi instalado no primeiro semestre de 2011, em área dos campos experimentais da Embrapa Hortaliças, localizados em Brasília-DF. As sementes utilizadas no plantio haviam sido armazenadas em câmara fria à temperatura de $10 \pm 2^{\circ} \mathrm{C}$, logo após a sua extração. Dez sementes de cada material foram semeadas, em 19 de novembro de 2010, em bandeja de poliestireno de 72 células $(45 \times 45 \times 115$ $\mathrm{mm})$ contendo substrato comercial à base de fibra de coco. As bandejas foram mantidas em casa de vegetação até o transplantio para o campo, no estádio de 4 a 6 pares de folhas definitivas. $O$ delineamento estatístico utilizado foi blocos casualizados com 16 tratamentos (acessos) e três repetições, sendo a parcela experimental constituída por três plantas cada.

O espaçamento utilizado foi de 1,0 $\mathrm{m}$ entre linhas e $0,5 \mathrm{~m}$ entre plantas, que foram conduzidas por estaqueamento logo após o transplantio das mudas para o campo e sempre que necessário. A adubação da cultura foi realizada no sulco de plantio, utilizando-se $1 \mathrm{~kg}$ de esterco de cama de frango, $1 \mathrm{~kg}$ de termofosfato magnesiano e $1 \mathrm{~kg}$ da formulação NPK 12-14-8 por metro linear. Outros tratos culturais como adubação de cobertura e poda foram feitos de acordo com orientações agronômicas descritas em Ribeiro et al. (2008).

\section{Caracterização morfoagronômica}

Caracterização morfológica - Na caracterização morfológica dos acessos, utilizou-se a chave para identificação de espécies e variedades domesticadas e semidomesticadas do gênero Capsicum (Ribeiro et al., 2008). A caracterização foi realizada com base em nove descritores recomendados pelo Bioversity International (ex-IPGRI International Plant Genetic Resources Institute, IPGRI, 1995), sendo cinco de parte vegetativa (hábito de crescimento; pilosidade; posição da flor; altura da planta; número de flores por axila) e quatro descritores para fruto (largura; comprimento; coloração quando maduro; coloração das sementes). Também, foram coletadas informações sobre precocidade dos materiais considerando a data do início da floração e a data do início da frutificação, a partir da data de semeadura.

Produtividade - Foi estimada de acordo com três colheitas realizadas, em intervalos semanais, sendo a primeira, cinco meses após o transplantio das mudas para o campo, 22/04/2011, e as demais, em 29/04/2011 e 06/05/2011. Para cada acesso, a colheita de frutos foi feita apenas na planta central, correspondendo à área útil de cada parcela, tendo sido coletados todos os frutos maduros da planta.

Posteriormente, os frutos foram pesados visando estabelecer o rendimento por planta. $\mathrm{Na}$ análise estatística dos resultados de produtividade, após a confirmação da distribuição normal dos dados, utilizou-se o teste F a $1 \%$ de significância e, em seguida, realizou-se o teste Scott-Knott a 5\% de significância, para comparação das médias. Os dados de produtividade foram transformados para $\sqrt{\mathrm{X}}$ para realização das análises estatísticas, entretanto, são apresentados em seus valores originais.

\section{Incidência de viroses}

A avaliação da incidência de viroses foi feita por meio da coleta de folhas de plantas individuais de pimenta 
cumari, em maio de 2011 e análise sorológica realizada segundo Clark \& Adams (1977), com utilização de antissoros policlonais. Foram testadas 139 amostras (Tabela 2) em dot-Elisa [Cucumber mosaic virus (CMV)] e DAS-ELISA [Double antibody sandwich - Enzyme-linked immunosorbent assay; Tomato spotted wilt virus (TSWV); Groundnut ringspot virus (GRSV); Tomato chlorotic spot virus (TCSV); Potato virus Y (PVY); Pepper mild mottle virus (PMMoV); Pepper yellow mosaic virus (PepYMV)].

DAS-ELISA - Utilizaram-se anticorpos produzidos contra a capa proteica de TSWV, GRSV, TCSV, PVY, PMMoV e PepYMV, produzidos na Embrapa Hortaliças. O IgG e o conjugado para as detecções virais foram utilizados na concentração de $1 \mathrm{mg} / \mathrm{mL}$. As placas contendo antissoro $(150 \mu \mathrm{L}$ por poço $)$ foram incubadas à temperatura de $4^{\circ} \mathrm{C}$ overnight. $\mathrm{O}$ antígeno $(150 \mu \mathrm{L} /$ poço) foi preparado pela maceração de folhas coletadas de pelo menos três ramos na planta em tampão de extração $(1,4$ $\mathrm{M} \mathrm{NaCl} ; 0,02 \mathrm{M} \mathrm{KH}_{2} \mathrm{PO}_{4} ; 0,08 \mathrm{M}$ $\left.\mathrm{Na}_{2} \mathrm{HPO}_{4} \cdot 12 \mathrm{H}_{2} \mathrm{O} ; 0,02 \mathrm{M} \mathrm{KCl} ; \mathrm{pH} 7,4\right)$, na proporção de 1:10 (p:v; g/mL). As placas foram incubadas à temperatura de $37^{\circ} \mathrm{C}$ por $2,5-3 \mathrm{~h}$. Adicionou-se o conjugado (100 $\mu \mathrm{L} /$ poço) aos poços e as placas mantidas a $37^{\circ} \mathrm{C}$ por $2,5-3 \mathrm{~h}$. Entre cada duas etapas, as placas foram lavadas três vezes com tampão PBS-Tween, permanecendo dentro dos poços por cerca de 5 minutos. A revelação foi realizada com $\rho$-fosfato de nitrofenil em tampão diethanolamina $(0,6 \mathrm{mg} / \mathrm{mL})$ e as placas mantidas na ausência de luz até o surgimento da reação. A leitura da absorbância foi feita em leitora de placas (Titertek Multiskan) no comprimento de onda de $405 \mathrm{~nm}$. A amostra foi considerada positiva quando o valor da leitura da absorbância foi pelo menos três vezes superior ao valor médio da absorbância do extrato da planta sadia.

Dot-ELISA - O extrato da planta preparado em tampão $1 / 2 \mathrm{PBS}$ foi depositado $(5 \mu \mathrm{L})$ em membrana de nitrocelulose (Millipore), seguido da fase de bloqueio, por imersão em $2 \%$ de leite em pó desnatado em $1 / 2 \mathrm{PBS}$, por 2-3 h. A membrana foi então imersa em $1 / 2 \mathrm{PBS}$ contendo antissoro específico na diluição de 1:1000 (v:v), por $24 \mathrm{~h}$. Incubou-se a membrana no conjugado geral (anticorpo conjugado à enzima fosfatase alcalina) em 1/2PBS por 2-3 $\mathrm{h}$. Entre cada duas etapas, procedeu-se à lavagem da membrana, três vezes, em $1 / 2 \mathrm{PBS}$, por 5 minutos. A revelação foi realizada em tampão $[100 \mathrm{mM} \mathrm{NaCl}$; $100 \mathrm{mM}$ Tris- $\mathrm{HCl} ; 5 \mathrm{mM} \mathrm{MgCl}\left(6 \mathrm{H}_{2} \mathrm{O}\right)$; $\mathrm{pH}$ 9,5] contendo BCIP (5-Bromo-4-chloro-3-indolyl phosphate) e NBT (Nitro blue tetrazolium). Todas as etapas foram conduzidas em agitador, à temperatura ambiente. As amostras positivas apresentaram-se como manchas de coloração arroxeada devido à formação de precipitado pela ação da enzima fosfatase alcalina sobre BCIP e NBT.

Para ambos os testes, os controles positivos foram preparados a partir de plantas Capsicum annuum cv. Ikeda (PepYMV; PMMoV), Datura stramonium (TSWV; GRSV; TCSV) e Nicotiana tabacum cv. TNN (PVY; CMV) inoculadas mecanicamente com cada um dos vírus, em casa de vegetação. Para os controles negativos, utilizou-se extrato de plantas não inoculadas.

Análises de agrupamento - Com o intuito de reunir informações obtidas a partir das diversas variáveis morfológicas e agronômicas avaliadas, foi realizada análise multivariada por meio de agrupamento (Cruz, 2008). Para isso, as variáveis polimórficas quantitativas (altura de planta; dias até floração; dias até frutificação; produtividade; comprimento de fruto; largura de fruto, e incidência de viroses) e qualitativas (variedade $C$. baccatum var. baccatum ou C. baccatum var. praetermissum; local de coleta; pilosidade, número de flores por axila, e cor do fruto maduro) foram transformadas em dados binários. A partir desses dados, os valores de dissimilaridade foram calculados pelo coeficiente de Jaccard e projetados em gráfico com três eixos e em dendrograma, estabelecido pelo método de agrupamento UPGMA (Unweighted Pair-Group Method Arithmetic Average), cujos valores de repetibilidade foram calculados com base em 1000 simulações bootstrap. As análises foram processadas e os gráficos construídos utilizando-se o módulo "diversidade genética" do software Genes
(Cruz, 2008). Para que fosse possível a conversão de dados quantitativos em binários, as classes foram estabelecidas pelo método prático de Sturges, em que o número de classes " $\mathrm{K}$ " é estabelecido pela fórmula $\mathrm{K}=1+3,32 \log \mathrm{n}$, sendo "n" equivalente ao número de observações, ou seja, 16 acessos.

\section{RESULTADOS E DISCUSSÃO}

Avaliação morfológica - Os resultados da caracterização morfológica revelaram a existência de variabilidade entre os acessos de pimenta cumari, tendo sido observadas diferenças para a maioria das características de planta e fruto estudadas (Tabela 2).

A altura média das plantas foi de $61,34 \mathrm{~cm}$, variando entre $32,17 \mathrm{~cm}$ (CNPH 3811) e 95,00 cm (CNPH 3817). Esta característica é considerada muito importante, pois plantas com altura inferior a $50 \mathrm{~cm}$, tendem a tornar a colheita mais difícil de ser realizada, requerendo maior esforço por parte dos trabalhadores rurais que devem se agachar ou mesmo se sentar em bancos situados próximos às plantas para colher os frutos (Ribeiro et al., 2008), aumentando os custos de produção.

O hábito de crescimento foi uma das características que apresentou menor variação, considerando-se que 15 dos 16 acessos avaliados foram caracterizados com hábito de crescimento intermediário. Somente o CNPH 3993 foi classificado como intermediário/prostrado.

A maioria dos materiais analisados no experimento não apresentou pilosidade em hastes e folhas, contudo, para dois acessos, verificou-se muita (CNPH 2964) e moderada pilosidade (CNPH 2948), tanto nas folhas quanto nos ramos. A pilosidade pode ter efeito direto sobre vetores de doenças (Almeida-Cortez, 2005), dificultando o acesso de insetos à planta. No entanto, plantas destes dois materiais apresentaram infecção por vírus em campo (Tabela 3), apesar de visualmente vigorosas, sugerindo, portanto, a existência de possível tolerância à infecção viral.

Alguns estudos têm mostrado que tricomas podem atuar de diversas maneiras sobre os insetos (Melo \& Silva 
Tabela 1. Identificação, tipo, local de coleta e classificação botânica de 16 acessos de pimenta cumari do Banco de Germoplasma de Capsicum da Embrapa Hortaliças (identification, type, collection place and botanical classification of cumari hot pepper accesions of the Capsicum Germplasm Bank of Embrapa Vegetables). Brasília, Embrapa Hortaliças, 2011.

\begin{tabular}{|c|c|c|c|}
\hline Acesso (identificação) & Pimenta (tipo) & Local de coleta & Classificação \\
\hline CNPH 2935 & Cumari & $\mathrm{ni}^{1}$ & C. baccatum var.baccatum \\
\hline CNPH 2957 & Cumari & Alto Caparão, MG & C. baccatum var.baccatum \\
\hline CNPH 3347 & Cumari & Lagoa Santa, MG & C. baccatum var.baccatum \\
\hline CNPH 3811 & Cumari & Viçosa, MG & C. baccatum var.baccatum \\
\hline CNPH 3824 & Cumari & Itapecerica, MG & C. baccatum var.baccatum \\
\hline CNPH 2948 & Cumari & ni & C. baccatum var.praetermissum \\
\hline CNPH 2964 & Cumari & Caldas, MG & C. baccatum var.praetermissum \\
\hline CNPH 3699 & Cumari & Piracanjuba, GO & C. baccatum var. praetermissum \\
\hline CNPH 3817 & Cumari & Turvânia, GO & C. baccatum var. praetermissum \\
\hline CNPH 3825 & Cumari & Itapecerica, MG & C. baccatum var. praetermissum \\
\hline CNPH 3912 & Cumari verdadeira & Campo Grande, MT & C. baccatum var. praetermissum \\
\hline CNPH 3992 & Cumari vermelha grande & Campo Florido, $\mathrm{MG}$ & C. baccatum var.baccatum \\
\hline CNPH 3993 & Cumari vermelha firme & Campo Florido, $\mathrm{MG}$ & C. baccatum var. baccatum \\
\hline CNPH 3997 & Cumari vermelha pequena & Campo Florido, $\mathrm{MG}$ & C. baccatum var. baccatum \\
\hline CNPH 4382 & Cumari & Embrapa Hortaliças, DF & C. baccatum ${ }^{2}$ \\
\hline CNPH 4065 & Cumari & Embrapa Hortaliças, DF & C. baccatum $^{2}$ \\
\hline
\end{tabular}

'ni= Dado não informado (not informed); ${ }^{2}$ variedade botânica não determinada (botanical variety not determined).

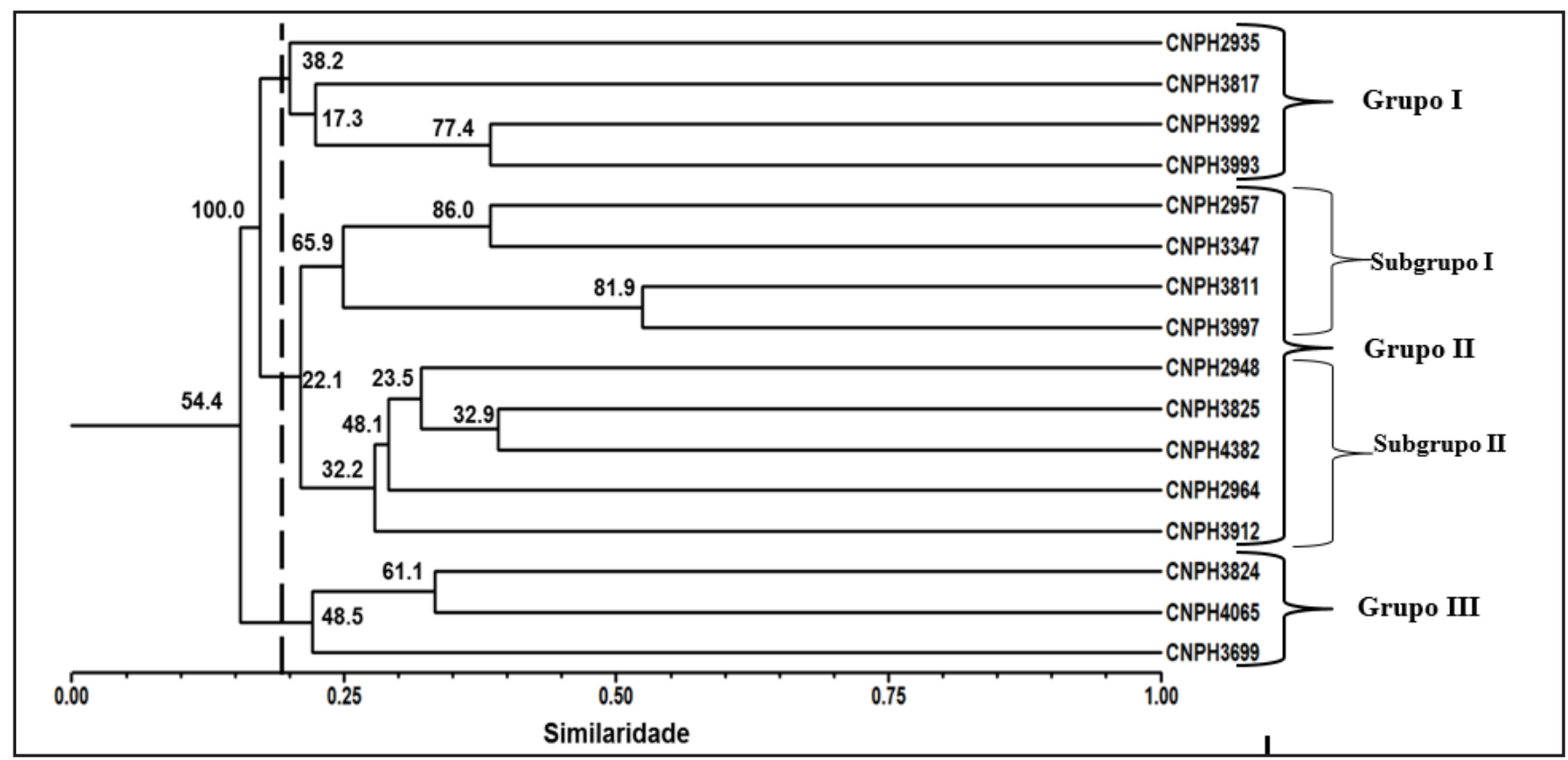

Figura 1. Similaridade entre 16 acessos de pimenta cumari (Capsicum baccatum var. baccatum e C. baccatum var. praetermissum) determinada com base em caracteres morfoagronômicos. Valores próximos aos nós correspondem à repetibilidade de formação dos grupos em 1000 simulações bootstrap. A linha pontilhada corresponde ao valor de dissimilaridade média $(0,19)$ \{dissimilarity among 16 accessions of cumari hot pepper (Capsicum baccatum var. baccatum and C. baccatum var. praetermissum) based on morpho-agronomic traits. Values placed close to knots correspond to repeatability based on 1000 bootstrap simulations. The traced line corresponds to the value of average dissimilarity (0.19)\}. Brasília, Embrapa Hortaliças, 2011.

Filho, 2002; Petters, 2002; Matos et al., 2009). Uma das formas seria como barreira química, liberando substâncias que podem ter efeito sobre alimentação, oviposição e sobrevivência, dentre outros aspectos (Krips et al., 1999;
Mishalska, 2003; Simmons \& Gurr, 2005), ou mesmo, compondo uma barreira física ao seu deslocamento na 
Tabela 2. Caracterização de 16 acessos de pimenta cumari para descritores de fruto, semente e planta (valores médios) \{characterization of 16 accessions of cumari hot pepper for fruit, seed and plant descriptors (average values)\}. Brasília, Embrapa Hortaliças, 2011.

\begin{tabular}{|c|c|c|c|c|c|c|}
\hline Acesso (identificação) & $\begin{array}{c}\text { Altura } \\
(\mathrm{cm})\end{array}$ & Pilosidade & $\begin{array}{c}\text { Floraçãa } \\
\text { (dias) }\end{array}$ & $\begin{array}{c}\text { Frutificação } \\
\text { (dias) }\end{array}$ & $\begin{array}{l}\text { Hábito de } \\
\text { crescimento }\end{array}$ & $\begin{array}{c}N^{\circ} \text { de flores } \\
\text { por axila }\end{array}$ \\
\hline CNPH 2935 & 84,70 & Ausente & 109 & 117 & Intermediário & 1 a 2 \\
\hline CNPH 2957 & 79,44 & Ausente & 126 & 132 & Intermediário & 2 \\
\hline CNPH 3347 & 66,11 & Ausente & 122 & 128 & Intermediário & 2 \\
\hline CNPH 3811 & 32,17 & Ausente & 105 & 143 & Intermediário & 2 \\
\hline CNPH 3824 & 73,77 & Pouca & 112 & 119 & Intermediário & 2 \\
\hline CNPH 2948 & 55,32 & Moderada & 109 & 125 & Intermediário & 2 a 3 \\
\hline CNPH 2964 & 45,79 & Muita & 91 & 110 & Intermediário & 1 a 2 \\
\hline CNPH 3699 & 52,21 & Pouca & 86 & 131 & Intermediário & 2 a 3 \\
\hline CNPH 3817 & 95,00 & Ausente & 101 & 114 & Intermediário & 2 \\
\hline CNPH 3825 & 54,66 & Ausente & 117 & 129 & Intermediário & 2 a 3 \\
\hline CNPH 3912 & 55,62 & Ausente & 114 & 126 & Intermediário & 1 \\
\hline CNPH 3992 & 63,84 & Ausente & 97 & 109 & Intermediário & 2 a 3 \\
\hline CNPH 3993 & 58,51 & Ausente & 105 & 113 & $\begin{array}{l}\text { Intermediário/ } \\
\text { Prostrado }\end{array}$ & 2 \\
\hline CNPH 3997 & 41,62 & Ausente & 104 & 127 & Intermediário & 1 \\
\hline CNPH 4382 & 45,52 & Ausente & 104 & 114 & Intermediário & 2 a 3 \\
\hline \multirow[t]{2}{*}{ CNPH 4065} & 77,21 & Ausente & 81 & 101 & Intermediário & 2 \\
\hline & $\begin{array}{c}\text { Posição da } \\
\text { flor }\end{array}$ & $\begin{array}{l}\text { Coloração do } \\
\text { fruto maduro }\end{array}$ & Comp & $\begin{array}{l}\text { mento do fruto } \\
(\mathrm{mm})\end{array}$ & $\begin{array}{l}\text { Largura do } \\
\text { fruto }(\mathbf{m m})\end{array}$ & $\begin{array}{c}\text { Coloração das } \\
\text { sementes }\end{array}$ \\
\hline CNPH 2935 & Ereta & Vermelho & & 11 & 5,0 & Amarela \\
\hline CNPH 2957 & Ereta & Vermelho claro & & 9 & 4,0 & Amarela \\
\hline CNPH 3347 & Ereta & Vermelho claro & & 12 & 3,0 & Amarela \\
\hline CNPH 3811 & Ereta & Vermelho & & 9 & 4,5 & Amarela \\
\hline CNPH 3824 & Ereta & Vermelho claro & & 7 & 6,0 & Amarela \\
\hline CNPH 2948 & Ereta & Vermelho & & 5 & 3,0 & Amarela \\
\hline CNPH 2964 & Ereta & Vermelho & & 12 & 5,0 & Amarela \\
\hline CNPH 3699 & Ereta & Vermelho claro & & 6 & 4,0 & Amarela \\
\hline CNPH 3817 & Ereta & Vermelho claro & & 9 & 6,0 & Amarela \\
\hline CNPH 3825 & Ereta & Vermelho & & 11 & 5,0 & Amarela \\
\hline CNPH 3912 & Ereta & Vermelho & & 13 & 5,0 & Amarela \\
\hline CNPH 3992 & Ereta & Vermelho & & 16 & 8,0 & Amarela \\
\hline CNPH 3993 & Ereta & Vermelho & & 9 & 2,0 & Amarela \\
\hline CNPH 3997 & Ereta & Vermelho & & - & - & Amarela \\
\hline CNPH 4382 & Ereta & - & & 8 & 5,0 & Amarela \\
\hline CNPH 4065 & Ereta & Vermelho & & 8 & 6,0 & Amarela \\
\hline
\end{tabular}

superfície das plantas. Dessa forma, é provável que acessos com essa característica venham a ser utilizados em programas de melhoramento genético, por constituírem potenciais fontes de resistência (Bespalhok Filho et al., 2007).

Matos et al. (2011) observaram relação direta entre a presença/ densidade de tricomas em pimentas do gênero Capsicum, especialmente em C. baccatum var. praetermissum e a resistência a artrópodes da espécie Polyphagotarsonemus latus. Segundo Matos et al. (2011), entre os acessos de pimentas domesticadas e semidomesticadas analisados, $C$. baccatum var. praetermissum apresentou elevada pilosidade. Os mesmos autores observaram, também, alta suscetibilidade de Capsicum frutescens a P. latus. Esta espécie de pimenta é caracterizada por possuir baixa densidade e reduzido comprimento de tricomas (Adedeji et al., 2007). Dessa forma, poderia se 
Tabela 3. Análise sorológica (DAS-ELISA) de plantas de 16 acessos de pimenta cumari do Banco de Germoplasma de Capsicum da Embrapa Hortaliças para sete espécies virais \{serological analysis (DAS-ELISA) of 16 cumari hot pepper accessions of the Capsicum Germplasm Bank of Embrapa Vegetables for seven viral species\}. Brasília, Embrapa Hortaliças, 2011.

\section{Plantas Infectadas (\%)}

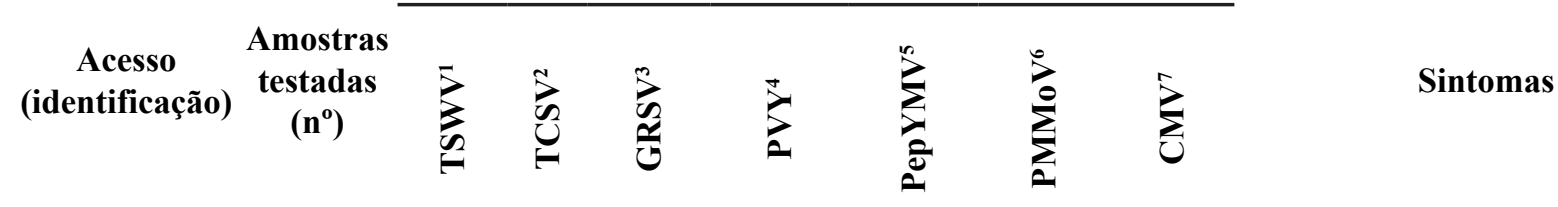

\begin{tabular}{|c|c|c|c|c|c|c|c|c|c|}
\hline CNPH 2935 & 9 & 44,44 & $--^{8}$ & - & 22,22 & - & 44,44 & 22,22 & Mosqueado \\
\hline CNPH 2948 & 6 & - & - & - & 33,33 & 33,33 & 33,33 & 16,67 & Mosqueado \\
\hline CNPH 2957 & 9 & - & - & 33,33 & 55,56 & 55,56 & 11,11 & 11,11 & $\begin{array}{l}\text { Mosaico; mosqueado; redução do } \\
\text { tamanho da folha }\end{array}$ \\
\hline CNPH 2964 & 8 & 12,50 & - & - & 37,50 & 25,00 & - & - & Mosqueado; mosaico \\
\hline CNPH 3347 & 9 & 44,44 & - & - & 33,33 & 33,33 & 11,11 & - & $\begin{array}{l}\text { Mosqueado; mosaico; redução do } \\
\text { tamanho da folha }\end{array}$ \\
\hline CNPH 3699 & 9 & 33,33 & - & - & 22,22 & 22,22 & - & - & Mosqueado; mosaico \\
\hline CNPH 3811 & 9 & - & - & 11,11 & 55,56 & 44,44 & 22,22 & 44,44 & Mosqueado; mosaico \\
\hline CNPH 3817 & 9 & - & - & 44,44 & 11,11 & 11,11 & 11,11 & 44,44 & Mosqueado; mosaico \\
\hline CNPH 3824 & 9 & 22,22 & - & & 22,22 & 55,56 & - & 33,33 & Mosqueado \\
\hline CNPH 3825 & 9 & - & - & 11,11 & 33,33 & 44,44 & - & - & Mosaico; mosqueado \\
\hline CNPH 3912 & 9 & 55,56 & - & - & 33,33 & 44,44 & 33,33 & 33,33 & $\begin{array}{l}\text { Ausência de folhas na planta na } \\
\text { época da avaliação }\end{array}$ \\
\hline CNPH 3992 & 9 & - & - & 44,44 & - & 33,33 & 33,33 & 22,22 & Mosqueado; mosaico \\
\hline CNPH 3993 & 9 & - & - & 44,44 & - & 33,33 & 44,44 & 44,44 & $\begin{array}{l}\text { Ausência de folhas na planta na } \\
\text { época da avaliação }\end{array}$ \\
\hline CNPH 3997 & 8 & - & - & 12,50 & 12,50 & 37,50 & 25,00 & 25,00 & Mosqueado \\
\hline CNPH 4065 & 9 & 22,22 & - & & 11,11 & 11,11 & - & - & Mosqueado \\
\hline CNPH 4382 & 9 & - & - & - & 22,22 & 44,44 & 11,11 & 11,11 & $\begin{array}{l}\text { Mosqueado; mosaico; redução do } \\
\text { tamanho da folha }\end{array}$ \\
\hline
\end{tabular}

${ }^{1} \mathrm{TSWV}=$ Tomato spotted wilt virus; ${ }^{2} \mathrm{TCSV}=$ Tomato chlorotic spot virus; ${ }^{3} \mathrm{GRSV}=$ Tomato spotted wilt virus; ${ }^{4} \mathrm{PVY}=\mathrm{Potato}$ virus $\mathrm{Y}$; ${ }^{5} \mathrm{PepYMV}=$ Pepper yellow mosaic virus; ${ }^{6} \mathrm{PMMoV}=$ Pepper mild mottle virus $;{ }^{7} \mathrm{CMV}=$ Cucumber mosaic virus; ${ }^{8}$ Vírus não detectado (virus not detected).

esperar que os acessos CNPH 2964 e CNPH 2948 apresentassem menor incidência de viroses, o que, entretanto, não foi observado no presente trabalho. Verificou-se, por outro lado, que CNPH 2964 e CNPH 2948 apresentaram destacado vigor em campo, sugerindo boa adaptação às condições de cultivo em campo aberto.

$\mathrm{O}$ número de flores por axila, atributo importante que auxilia na identificação de espécies, variou de um a três. A largura média do fruto variou entre $2 \mathrm{~mm}$ para CNPH 3993 e $8 \mathrm{~mm}$ para CNPH 3992. Com relação ao comprimento médio do fruto, houve variação entre $5 \mathrm{~mm}$ (CNPH 2948) e
16 mm (CNPH 3992). Segundo Rêgo (2001), determinadas características morfológicas como maior comprimento dos frutos e maior número de flores por axila possuem elevada importância em função da alta correlação entre estes e outros caracteres de interesse, como a produtividade.

Atributos como coloração das sementes e posição da flor não apresentaram variação, sendo nesse caso, considerados caracteres monomórficos. Todos os acessos avaliados foram caracterizados como possuindo sementes de coloração amarela, além de posição ereta da flor.

Avaliação agronômica - Verificou- -se que, para oito acessos $(50,00 \%$ dos materiais avaliados), a floração ocorreu entre 96 e 111 dias após a semeadura, para três $(18,75 \%)$, a floração ocorreu em menos de 96 dias e para cinco $(31,25 \%)$ em 112 ou mais dias. A frutificação iniciou-se em, aproximadamente, uma ou duas semanas, em média, depois desse período (Tabela 2). O acesso CNPH 4065 foi o mais precoce, com florescimento aos 81 dias após a semeadura. Segundo Ribeiro et al. (2008), materiais que florescem com aproximadamente 80 dias, como por exemplo, a pimenta murupi, podem ser considerados precoces. Como característica interessante do acesso CNPH 
Tabela 4. Produtividade estimada de 16 acessos de pimenta cumari do Banco de Germoplasma de Capsicum da Embrapa Hortaliças (estimated yield of 16 cumari hot pepper accessions of the Capsicum Germplasm Bank of Embrapa Vegetables). Brasília, Embrapa Hortaliças, 2011.

\begin{tabular}{|c|c|c|c|c|c|}
\hline $\begin{array}{l}\text { Acesso } \\
\text { (identificação) }\end{array}$ & $\begin{array}{c}\text { Média de } \\
\text { produtividade (g) }{ }^{1}\end{array}$ & $\begin{array}{c}\text { Acesso } \\
\text { (identificação) }\end{array}$ & $\begin{array}{c}\text { Média de } \\
\text { produtividade (g) }\end{array}$ & $\begin{array}{c}\text { Acesso } \\
\text { (identificação) }\end{array}$ & $\begin{array}{c}\text { Média de } \\
\text { produtividade (g) }\end{array}$ \\
\hline CNPH 4065 & $340 \mathrm{a}$ & CNPH 3817 & $84 \mathrm{c}$ & CNPH 3811 & $38 \mathrm{c}$ \\
\hline CNPH 3824 & $257 \mathrm{a}$ & CNPH 2935 & $70 \mathrm{c}$ & CNPH 4382 & $27 \mathrm{c}$ \\
\hline CNPH 3993 & $229 a$ & CNPH 3347 & $42 \mathrm{c}$ & CNPH 2957 & $22 \mathrm{c}$ \\
\hline CNPH 3992 & $161 \mathrm{~b}$ & CNPH 2964 & $48 \mathrm{c}$ & CNPH 2948 & $8 \mathrm{c}$ \\
\hline CNPH 3699 & $120 \mathrm{~b}$ & CNPH 3825 & $42 \mathrm{c}$ & CNPH $3997^{12}$ & - \\
\hline CNPH 3912 & $113 \mathrm{~b}$ & & & & \\
\hline
\end{tabular}

${ }^{1}$ Médias seguidas pela mesma letra não diferem entre si pelo teste Scott-Knott a 5\% de probabilidade. As médias apresentadas correspondem aos valores reais de produção por planta, no entanto, a análise foi feita com os dados transformados para $\sqrt{\mathrm{x}}$. Coeficiente de variação dos dados transformados $=28,74 \%$ (mean values followed by the same letter are not significantly different by the Scott-Knott test, $5 \%$. The average values presented herein are real values; however, statistical analysis was carried out using data transformed to $\sqrt{\mathrm{x}}$. Coefficient of variation of transformed data $=28.74 \%)$. ${ }^{2}$ Produtividade não estimada devido ao reduzido número de frutos obtidos para o acesso. $\left({ }^{2}\right.$ yield not estimated due to the low number of fruits obtained for this accession).

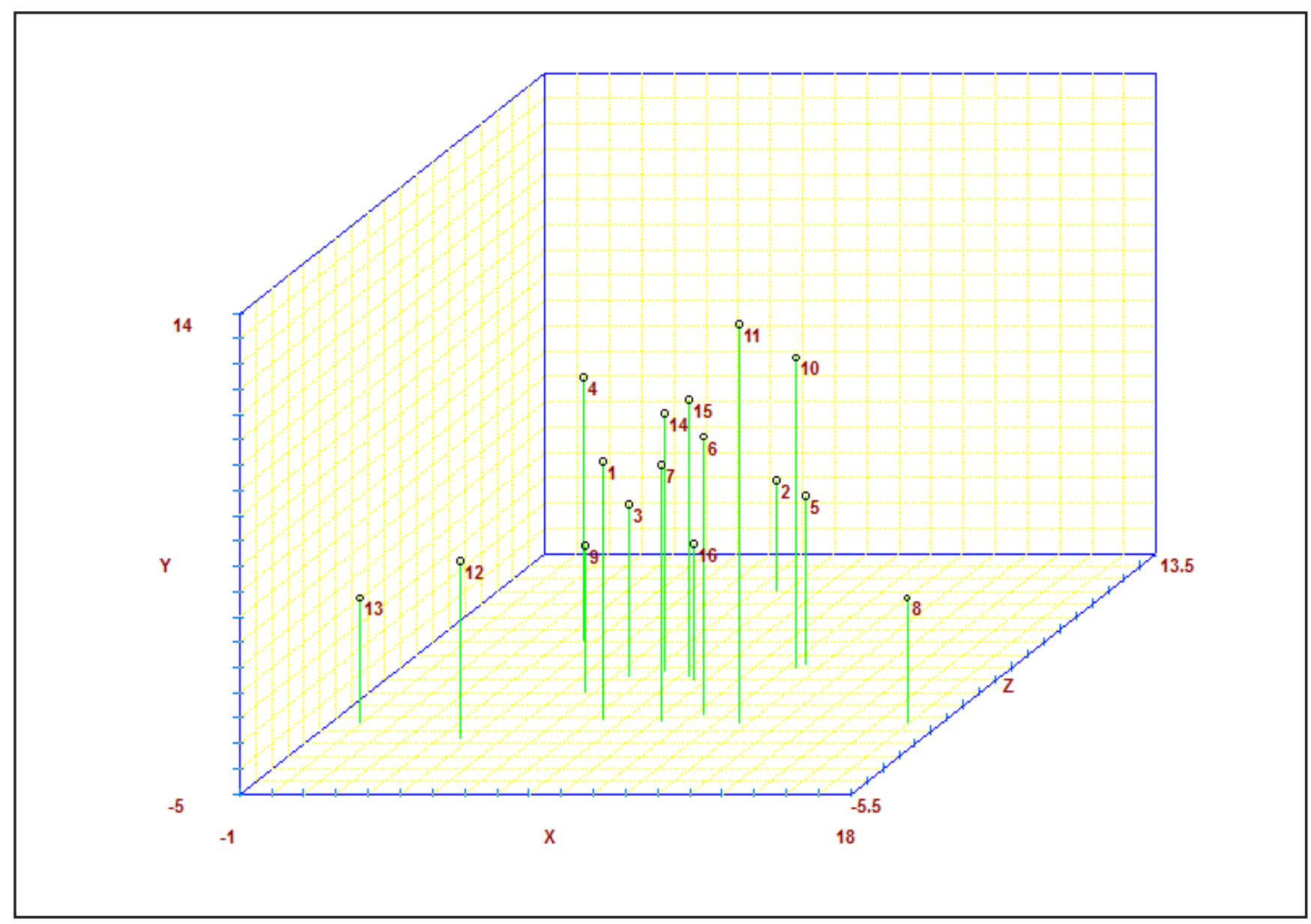

Figura 2. Análise de agrupamento de acessos de pimenta cumari. $1=\mathrm{CNPH} 2935 ; 2=\mathrm{CNPH} 2957 ; 3=\mathrm{CNPH} 3347 ; 4=\mathrm{CNPH} 3811 ; 5=$ CNPH 3824; $6=$ CNPH 2948; 7= CNPH 2964; 8= CNPH 3699; 9= CNPH 3817; $10=\mathrm{CNPH} 3825 ; 11=\mathrm{CNPH} 3912 ; 12=\mathrm{CNPH} 3992$; $13=\mathrm{CNPH} 3993 ; 14=\mathrm{CNPH} 3997 ; 15=\mathrm{CNPH} 4382 ; 16=\mathrm{CNPH} 4065$. Acessos indicados pelos números $1 ; 2 ; 3 ; 4 ; 5 ; 12 ; 13 ; 14$ são classificados como Capsicum baccatum var. baccatum e os indicados por 6; 7; 8; 9; 10; 11 como C. baccatum var. praetermissum, acessos 15 e 16 não foram caracterizados (grouping analysis of cumari hot pepper genotypes. $1=\mathrm{CNPH} 2935 ; 2=\mathrm{CNPH} 2957 ; 3=\mathrm{CNPH} 3347$; $4=$ CNPH 3811; 5= CNPH 3824; 6= CNPH 2948; 7= CNPH 2964; 8= CNPH 3699; 9= CNPH 3817; $10=\mathrm{CNPH} 3825 ; 11=\mathrm{CNPH} 3912 ; 12=$ CNPH 3992; $13=$ CNPH 3993; 14= CNPH 3997; 15= CNPH 4382; 16= CNPH 4065. Accessions indicated by the numbers $1 ; 2 ; 3 ; 4 ; 5 ; 12$; 13; 14 are Capsicum baccatum var. baccatum and 6; 7; 8; 9; 10; 11 are C. baccatum var. praetermissum. Accessions 15 and 16 were not characterized). Brasília, Embrapa Hortaliças, 2011. 
4065, destacou-se o seu aparente alto potencial produtivo (Tabela 4).

O acesso CNPH 3699 também se destacou por sua precocidade, com florescimento aos 86 dias após a semeadura, sendo este o menor período entre os acessos de C. baccatum var. praetermissum, CNPH 2948 (109 dias), CNPH 2964 (91 dias), CNPH 3817 (101 dias), CNPH 3825 (117 dias) e CNPH 3912 (114 dias).

Depois de verificada a existência de diferença significativa entre os tratamentos, os acessos foram divididos em três grupos distintos de produtividade por meio do teste de agrupamento de médias Scott-Knott (Tabela 4). O primeiro grupo, cuja produtividade variou de 229 a 340 gramas por planta, foi composto pelos acessos CNPH 4065, CNPH 3824 e CNPH 3993. Vale ressaltar que dois desses acessos (CNPH 3824 e CNPH 3993) são C. baccatum var. baccatum, entretanto, o outro acesso (CNPH 4065) ainda não foi caracterizado quanto à variedade botânica dentro da espécie. Plantas dos representantes deste grupo de produtividade (Grupo I) também se mostraram vigorosas em campo, mesmo nos casos em que foram identificadas infecções causadas por vírus caracterizadas pela presença de sintomas menos severos, como mosqueado (CNPH 4065; CNPH 3824), confirmadas por análises sorológicas (Tabela 2).

O segundo grupo, composto pelos materiais CNPH 3912, CNPH 3699 e CNPH 3992, apresentou estimativa de produtividade intermediária em relação aos demais acessos, variando entre 113 gramas e 161 gramas por planta. Característica marcante destes acessos foi a alta suscetibilidade a viroses, confirmada por meio de testes sorológicos. Sintomas típicos das viroses, como mosqueado ou mosaico, redução do tamanho de folhas e deformação foliar foram encontrados em quase todas as plantas desses acessos.

O terceiro (Grupo III), composto por nove acessos, é caracterizado pela baixa produtividade relativa e alta incidência e severidade de viroses. Entre esses, destacaram-se CNPH 2964 e CNPH 2948 em função da presença de pilosidade. A produtividade do acesso CNPH 3997 não pôde ser estimada de- vido à baixa produção verificada, com a obtenção de apenas alguns frutos, que possibilitaram apenas sua caracterização parcial, entretanto, não a quantificação da massa produzida. Características como comprimento e largura também não puderam ser avaliadas para frutos desse material.

A variação da estimativa de produtividade entre os materiais avaliados foi de $4200 \%$ (de $8 \mathrm{~g} /$ planta a $340 \mathrm{~g} /$ planta). $\mathrm{O}$ acesso com potencial de produtividade mais elevado (CNPH 4065) apresentou rendimento estimado em 6,8 $\mathrm{t} /$ ha no espaçamento de 1,0x0,5 m. Esses resultados são divergentes dos observados por Ribeiro et al. (2006) ao analisar o desempenho produtivo do acesso CNPH 3770 (pimenta cumari), obtendo produção média de $1.060 \mathrm{~g} / \mathrm{planta}$, com produtividade média estimada de $11 \mathrm{t} /$ ha. No entanto, os resultados do presente estudo foram próximos dos obtidos por Gonçalves (2004), que descreveu o rendimento médio de produtividade de cumari em $4 \mathrm{t} / \mathrm{ha}$.

Incidência de viroses - Constatou-se a predominância dos potyvírus sobre os tospovírus nas condições do período em que foi realizada a avaliação (novembro 2010 a maio 2011). Os vírus mais frequentemente detectados foram PepYMV em 33\% das plantas analisadas, seguido por PVY com $25 \%$. Considerando os tospovírus, TSWV ocorreu em 31 plantas (22\%), GRSV em 22 (14\%), enquanto que TCSV não foi encontrado. CMV e PMMoV foram detectados em 27 (19\%) e 24 (17\%) plantas, respectivamente (Tabela 3 ).

O PMMoV, por ser transmitido mecanicamente durante a realização dos tratos culturais e, também, por meio de sementes infectadas, tem sido intensamente disseminado em áreas produtoras de pimentão (Capsicum annuum) nos últimos anos, causando perdas significativas em diversas áreas produtoras do Panamá (Herrera-Vasquez et al., 2009). Jarret et al. (2008) relatam a detecção desta espécie de tobamovírus em 32\% dos acessos do acervo de Capsicum do Banco de Germoplasma dos Estados Unidos. A alta porcentagem de detecção de acessos infectados com PMMoV no trabalho desses autores evidencia o elevado potencial de disseminação do vírus. Vale ressaltar que ainda não há medidas eficazes de controle para o tratatamento e eliminação desse patógeno em sementes infectadas, considerando-se que as partículas virais mantêm sua capacidade infectiva mesmo em casos em que a semente infectada é armazenada por períodos prolongados em câmaras frias (Genda et al., 2005).

O PepYMV é considerado como um dos vírus predominantes nas culturas da pimenta e do pimentão no Brasil (Lopes \& Ávila, 2003; Lima et al., 2010). No presente trabalho, PepYMV foi o mais detectado em plantas dos diversos acessos de cumari, reafirmando a importância desse patógeno para a cultura. Juhasz et al. (2006) observaram perdas de até $100 \%$ na produção em lavouras de tomate devido à infecção por PepYMV. Em função de sua alta incidência e das perdas que pode causar na produção, a obtenção de cultivares resistentes a esse vírus tem sido uma das prioridades nos programas de melhoramento genético de pimenta e pimentão em desenvolvimento no país nos últimos anos (Rezende, 2015).

As análises de agrupamento ilustraram a existência de variabilidade entre os materiais avaliados (Figuras 1 e 2). Verificou-se, na Figura 1, a formação de três grupos distintos ao se considerar o corte do dendrograma em posição equivalente ao valor de similaridade média $(0,19)$. A divisão entre os três grupos estabelecidos, no entanto, não coincidiu completamente com a divisão das variedades botânicas estudadas, havendo pelo menos um material de cada variedade botânica presente em cada um dos grupos.

Considerando-se o Grupo II, dois subgrupos puderam ser identificados, com similaridade um pouco superior à média, separando as duas variedades botânicas estudadas. O primeiro subgrupo reuniu exclusivamente acessos de C. baccatum var. baccatum (CNPH 2957; CNPH 3347; CNPH 3811; CNPH 3997) e o segundo, com a exceção de CNPH 4382 (acesso não caracterizado), foi constituído exclusivamente por $C$. baccatum var. praetermissum (CNPH 2948; CNPH 3825; CNPH 2964; CNPH 3912).

Dois dos três materiais mais produ- 
tivos, CNPH 4065 e CNPH 3824, foram agrupados com valor de similaridade de aproximadamente 0,35 , superior à média. No entanto, outro material pertencente a esse mesmo grupo, CNPH 3993, apresentou-se relativamente distante dos dois acessos citados anteriormente, indicando a possibilidade de futuros cruzamentos associando produtividade e vantagens resultantes da variabilidade genética existente entre eles. Ressalta-se, por outro lado, que até mesmo os materiais mais próximos (CNPH 3811; CNPH 3997), quando comparados, apresentaram considerável grau de variabilidade entre si (similaridade $=0,55)$.

O gráfico de projeção (Figura 2) enfatizou a variabilidade dos acessos CNPH 3699, CNPH 3992, CNPH 3993 , CNPH 3912 e CNPH 3825 em relação aos demais. É interessante observar que CNPH 3993, um dos materiais com elevado potencial produtivo, apresentou variabilidade relativamente alta em relação aos demais acessos avaliados, sendo assim, considerado promissor para cruzamentos.

No presente trabalho, detectou-se grande variabilidade entre e dentro das variedades botânicas Capsicum baccatum var. praetermissum e $C$. baccatum var. baccatum, considerando-se as diferenças nas características morfológicas e agronômicas entre os diversos materiais.

Os acessos considerados mais promissores foram aqueles que apresentaram características morfoagronômicas de interesse, como baixa incidência de viroses e maior potencial produtivo (CNPH 4065; CNPH 3824; CNPH 3993), precocidade (CNPH 4065) e alta pilosidade (CNPH 2964; CNPH 2948).

\section{AGRADECIMENTOS}

À Embrapa Hortaliças pela disponibilização dos acessos de pimenta utilizados nos experimentos, bem como da infraestrutura. À Universidade de Brasília e ao CNPq pelo suporte durante a condução das atividades.

\section{REFERÊNCIAS}

ADEDEJI, O; AJUWON, OY; BABAWALE, OO. 2007. Foliar epidermal studies, organographic distribution and taxonomic importance of trichomes in the family Solanaceae. International Journal of Botany 3: 276-282.

ALMEIDA-CORTEZ, J. 2005. Herbivoria e mecanismos de defesa vegetal. In: NOGUEIRA, RJMC; ARAÚJO, EL; WILLADINO, LG; CAVALCANTE, UMT (org). Estresses ambientais: danos e beneficios em plantas. Recife: UFRPE. p.389-396.

BESPALHOK FILHO, JC; GUERRA, EP; OLIVEIRA, R. 2007. Melhoramento para resistência a doenças. In: BESPALHOK FILHO, JC; GUERRA, EP; OLIVEIRA, R (eds). Melhoramento de Plantas. Curitiba: UFPR. p.11-18.

CARVALHO, SIC; BIANCHETTI, L; BUSTAMANTE, PG; SILVA, DB. 2003. Catálogo de germoplasma de pimentas e pimentões (Capsicum spp.) da Embrapa Hortaliças. Brasília: Embrapa Hortaliças. 49p.

CLARK, MF; ADAMS, AN. 1977. Characteristics of the microplate method of enzyme linked immunosorbent assay for the detection of plant viruses. Journal of General Virology 34: 475-483.

CRUZ, CD. 2008. Programa Genes: diversidade genética. Viçosa: Editora UFV. 278p.

DeWITT, D; BOSLAND, PW. 2009. The complete Chile pepper book: a gardener's guide to choosing, growing, preserving and cooking. London: Timber Press. 336p.

FAO. 2012. Faostat. Disponível em: http://www. faostat.fao.org/. Acessado em: 21 mar. 2013.

GENDA, Y; SATO, K; NUNOMURA, O; HIRABAYASHI, T; OHNISHI, J; TSUDA, S. 2005. Immunolocalization of Pepper mild mottle virus in Capsicum annuum seeds. Journal of General Plant Pathology 71: 238-242.

GONÇALVES, EMD. 2004. Produção de pimenta em assentamentos rurais no município de Campo Florido-MG. In: ENCONTRO NACIONAL DO AGRONEGÓCIO PIMENTAS (Capsicum spp.), 1.; MOSTRA NACIONAL DE PIMENTAS E PRODUTOS DERIVADOS, 1., 2004, Brasília. Palestras... Brasília: Embrapa Hortaliças, CD-ROM.

HERRERA-VASQUEZ, JA; CORDOBASELLES, MC; CEBRIAN, MC; ALFAROFERNANDEZ, A; JORDA, C. 2009. First report of Pepper mild mottle virus and Tobacco mild green mosaic virus infecting pepper in Panama. Plant Pathology 58: 786-786.

IPGRI. 1995. Descriptors for Capsicum (Capsicum spp.). Rome: IPGRI. 49p.

JARRET, RL; GILLASPIE, AG; BARKLEY, NA; PINNOW, DL. 2008. The occurrence and control of pepper mild mottle virus (PMMoV) in the USDA/ARS Capsicum germplasm collection. Seed Technology Journal 30: 26-36.

JUHASZ, ACP; SILVA, DJH; ZERBINI JÚNIOR, FM; SOARES, BO; AGUILERA, GAH. 2006. Screening of Lycopersicon $s p$. accessions for resistance to pepper yellow mosaic virus. Scientia Agricola 63: 510-512.
KRIPS, OE; KLEIJN, PW; WILLEMS, PEL; GOLS, GJZ; DICKE, M. 1999. Leaf hairs influence searching efficiency and predation rate of the predatory mite Phytoseiulus persimilis (Acari: Phytoseiidae). Experimental and Applied Acarology 23: 119-131.

LIMA, MF; MELO, WF; VALE, LSR; MORGADO, HS; INOUE-NAGATA, AK; REIFSCHNEIDER, FJB. 2010. Detecção e incidência de vírus em 89 acessos de pimenta (Capsicum spp.) no Município de Ceres, Goiás. Horticultura Brasileira 28: S1187-S1194.

LOPES, CA; ÁVILA, AC. 2003. Doenças do pimentão: diagnose e controle. Brasília: Embrapa Hortaliças, 96p.

MATOS, CHC; PALLINI, A; PINTO, CMF; VENZON, M; REZENDE, DDM; FREITAS, RCP. 2011. Caracterização morfológica e classificação da superfície foliar de pimentas quanto à presença de tricomas e domácias. Horticultura Brasileira 29: 181-186.

MATOS, CHC; PALLINI, A; VENZON, M; FREITAS, RCP; REZENDE, DDM; SCHOEREDER, JH. 2009. Os tricomas de Capsicum spp. interferem nos aspectos biológicos do ácaro-branco Polyphagotarsonemus latus Banks (Acari: Tarsonemidae). Neotropical Entomology 38: 589-594.

MELO, MO; SILVA-FILHO, MC. 2002. Plantinsect interaction: an evolutionary arms race between two distinct defense mechanisms. Brazilian Journal of Plant Physiology 14: 71-81.

MISHALSKA, K. 2003. Clibing of leaf trichomes by eriophyid mites impedes their location by predators. Journal of Insect Behavior 16: 833-844.

PETTERS, PJ. 2002. Correlations between leaf structural traits and the densities of herbivorous insect guilds. Biological Journal of the Linnean Society 77: 43-65.

RÊGO, ER. 2001. Diversidade, herança e capacidade combinatória em pimenta (Capsicum baccatum). Viçosa: UFV. 117p. (Tese doutorado).

REZENDE, JF. 2015. Novo gene de resistência ao Pep YMV em Capsicum annuum L. Lavras: UFLA. 58p. (Dissertação mestrado).

RIBEIRO, CSC; FREITAS, IC; CARVALHO, SIC. 2006. Produção de pimentas diversas na região do Bico de Papagaio-TO. In: CONGRESSO BRASILEIRO DE OLERICULTURA, 46. Resumos... Goiânia: ABH (CD-ROM).

RIBEIRO, CSC; LOPES, CA; CARVALHO, SIC; HENZ, GP; REIFSCHNEIDER, FJB. 2008. Pimentas Capsicum. Brasília: Embrapa Hortaliças. 200p.

SIMMONS, AT; GURR, GM. 2005.Trichomes of Lycopersicon species and their hybrids: effects on pests and natural enemies. Agricultural and Forest Entomology 7: 265-276. 